\title{
Sobre o protagonismo na linguagem escrita e novos modos de interação
}

\section{On the protagonism in written language and new modes of interaction}

Djane Antonucci Correa*

Universidade Estadual de Ponta Grossa

Ponta Grossa, Paraná / Brasil

\begin{abstract}
RESUMO: O objetivo deste trabalho é problematizar o protagonismo da linguagem escrita a partir da retomada de estudos anteriores, Correa (2009; 2011a) e também Correa (2014). Para tanto, inicialmente, trago discussões sobre o conceito de língua e, em um segundo momento, trago algumas reflexões sobre agência e agenciamento. Em seguida, retomo estudos anteriores sobre a linguagem escrita para abordá-la numa visão pragmática. Por fim, trago dois exemplos para estabelecer conexões entre o pensamento hegemônico acerca da escrita em contraponto à visão descolonizada de escrita, de modo que concluo chamando a atenção para a necessidade de descolonizar o intelecto.
\end{abstract}

PALAVRAS-CHAVE: descolonização do pensamento; práticas de linguagem escrita; subalternização.

ABSTRACT: This work resumes previous studies by Correa (2009; 2011a) and also Correa (2014) aiming at questioning the role of written language. First, the concept of language is addressed, and then some reflections on agency are developed. Next, previous studies on written language are referred to approaching it in a pragmatic view. Finally, two examples are provided to establish connections between the hegemonic thought about writing as opposed to the decolonized view of writing. The conclusion draws attention to the necessity of decolonizing the intellect.

KEYWORDS: decolonizing thought; written language practices; subordination.

\section{Introdução}

As muitas vozes que ecoam e criam a(s) realidade(s) com que convivemos sustentam as ideias com as quais tento estabelecer conexões neste texto. Entre tantas, busco trazer para a discussão o protagonismo da/ na linguagem escrita contemporaneamente para pensar sobre quem seria (ou

\footnotetext{
*djanecorrea@uol.com.br, djaneantonucci@gmail.com
} 
quais seriam) esse(s) protagonista(s). Parto do princípio de que as práticas linguísticas são heterogêneas "e sustentam uma polifonia recombinante" (PINTO, 2012; 2014), de modo que se redesenham continuamente. Além disso, as práticas de linguagem estão além das manifestadas por meio das linguísticas propriamente ditas.

Para entender melhor e tentar expandir a discussão sobre as possibilidades de compreensão das práticas de linguagem escrita na contemporaneidade, notadamente com o advento da linguagem multimodal, das diversas redes sociais e das práticas de interação que não estão restritas aos recursos linguísticos, é preciso adequar e compartilhar modos de interação considerando o que foi dito em Correa (2014), ou seja, as circunstâncias que afetam ou definem o que temos como língua, não o que defendemos que temos ou gostaríamos de ter. Trata-se, de um lado, da língua que insiste em permanecer no imaginário das pessoas, mas não toma parte nas interações cotidianas e, de outro, do contrapé das práticas linguísticas efetivas. Além destas, como já dito, é preciso ter em conta as práticas de linguagem mais amplas, que vão além das expressas por meio de recursos linguísticos.

Kramsch (2014) observa que, com o advento da globalização e a crescente mobilidade das pessoas, produtos e capital, a natureza multilíngue e multicultural das sociedades nacionais tem se tornado tanto mais predominante quanto mais visível.

A globalização, em conjunto com a mídia global e as tecnologias de comunicação global, tem exacerbado a multiplicidade de códigos, os meios e formas de dar sentido à vida cotidiana. Se olharmos para a forma como os jovens de hoje utilizam a língua no Facebook, Twitter e em suas mensagens de texto, notamos uma proliferação da atividade semiótica, um desrespeito saudável pela autoridade acadêmica (regras e convenções ortográficas, gramaticais e lexicais), hibridismos e alternância de códigos, explosões multimodais de criatividade e inovação. (KRAMSCH, 2014, p. 10)

Retomando o estudo inicial de Correa (2009; 2011a; 2011b) e também de Correa (2014), problematizo a ideia do protagonismo na linguagem escrita. Parto, inicialmente, de discussões sobre o conceito de língua (CORREA; GÜTHS, 2015; PINTO, 2012; 2014; 2015; RAJAGOPALAN, 2014a; 2014b;). Em um segundo momento, trago algumas reflexões sobre agência e agenciamento (AHEARN, 2000; 2001; ASAD, 2000; DURANTI, 2004; RAJAGOPALAN, 2013). Na terceira parte do artigo, retomo estudos 
anteriores (CORREA, 2009; 2011a; 2014) sobre a linguagem escrita (BRITTO, 2008; HARRIS, 2000) para abordá-la numa visão pragmática (BLOMMAERT, 2014; RAJAGOPALAN, 2014a; 2014b; MEY, 2014; PINTO, 2014; SILVA; FERREIRA; ALENCAR, 2014). Por fim, trago dois exemplos sobre o pensamento hegemônico acerca da escrita para contraponto à visão descolonizada (MIGNOLO, 2003) de escrita, de modo a chamar atenção para a necessidade de descolonizar o intelecto.

\section{Sobre o conceito de língua}

Em Correa (2011a; 2011b; 2014) está exposto que o investimento em estudos e em discussões sobre política linguística pode elucidar os motivos pelos quais a visão homogênea de língua insiste em perpetuar contradições e desafios nas mais diversas práticas sociais, mas principalmente nas práticas escolares, desconsiderando a heterogeneidade e tolhendo a autonomia daqueles que buscam fazer uso das suas línguas, como as línguas de imigração e indígenas, agindo de acordo com o ideal de monolinguismo (CORREA; GÜTHS, 2015).

[...] ao se olhar abertamente para o histórico das políticas linguísticas, é possível perceber como o Estado, por diversas vezes, utilizou-se da escola para colocar em prática suas políticas linguísticas que agiam no sentido de construir um ideal de nação que não deixava espaço para a diversidade. Ter em mente todas essas políticas é fundamental para que olhemos criticamente para o modo como a língua é ensinada na atualidade, para os currículos e para os documentos oficiais que norteiam o ensino, de modo a percebermos quais os discursos perpassam a noção de língua a ser trabalhada em sala de aula. (CORREA; GÜTHS, 2015, p. 157)

Para além do contexto brasileiro, Kramsch (2014), ao participar de um trabalho que foi fundamental para enriquecer uma coletânea sobre política linguística e ensino de língua (CORREA, 2014) e compartilhar conosco seus estudos, enfatiza que, nas últimas décadas, o trabalho dos professores de língua vem solicitando mudanças mediante os novos e diversos modos de interação.

Nos últimos trinta anos, a compressão do tempo e do espaço online e a capacidade ilimitada de armazenagem de informações do computador, sua onipresença e controle mudaram a natureza do que nós, enquanto professores de língua, somos instados a fazer. Ao invés de confiar exclusivamente nas palavras e sentenças para criar significado, 
agora temos imagens, filmes e os vídeos do YouTube para tornar o significado visível e palpável, acessível como nunca foi antes. Ao invés de negociações difíceis, de intenções ilocucionárias divergentes e de interpretações possivelmente conflitantes de eventos, agora temos chat rooms, blogs e Facebook que são ambientes mais descontraídos onde um grande número de "amigos" e um grande volume de participação são mais importantes do que a profundidade dos diálogos e a precisão elocucionária. Saber como navegar nas múltiplas fontes de informação e modalidades semióticas tem se tornado de importância crucial na aquisição da competência comunicativa. (KRAMSCH, 2014, p. 10-11)

Para refletir melhor sobre os efeitos dessa diversidade e, por outro lado, do que se define como "língua" mediante a visão que prepondera guiada por vertentes hegemônicas é importante ver primeiramente o papel do conceito no processo de construção e conhecimento.

Os conceitos estão no centro da atividade cognitiva; a aprendizagem é uma aquisição de conceitos; a crença é uma atitude cognitiva acerca de uma proposição (em que dois conceitos são articulados) na qual o sujeito adere ao conteúdo da proposição; a inferência é uma aplicação de conceitos (a objetos, a percepções); enquanto o raciocínio é um correlacionamento de inferências. Os conceitos intervêm igualmente no conhecimento: quando uma crença é verdadeira e justificada, podemos considerá-la como um conhecimento. Os conceitos e os conhecimentos são organizados habitualmente em taxonomias mais complexas: teorias. (HARDYVALLÉE, 2013, p. 17-18, grifos do autor)

Considerando que a aquisição de conceitos centraliza e objetiva mensurar a construção do conhecimento, é preciso levar em conta que eles são balizas indispensáveis para esse processo. Entretanto, na maioria das vezes, eles são vistos equivocadamente como autossuficientes, e, nessa perspectiva, limitam a visão sobre eles e, por extensão, a visão de mundo. Assim, repensar os aparelhos conceituais leva à reconstrução de conhecimentos e à revisão crítica deles. Nesse sentido, é preciso repensar parte de nossos aparelhos conceituais (BLOMMAERT, 2014). O autor faz essa recomendação ao trazer para discussão a ambivalência da palavra "poder", mostrando-a, por um lado, como força negativa, rejeitável; por outro lado, reinterpretando-a, a fim de obter uma visão mais equilibrada a seu respeito, uma vez que o poder pode tanto incluir quanto excluir, e associá-la imediatamente ao seu sentido negativo torna a compreensão do termo parcial, unilateral. 
Com efeito, atender aos vários aspectos que envolvem a (re)construção e a ampliação de conhecimentos requer uma visão pragmática da linguagem, notadamente quando se trata de práticas acadêmicas, as quais, como todas, estão estreitamente ligadas às práticas sociais. Pinto (2014) traz em suas pesquisas o ponto de vista da pragmática. Trata-se de estudos que defendem que discursos e práticas são performativos, ou seja, são atos de fala repetidos que produzem efeitos que constroem o que alegam descrever (AUSTIN, 1976; BUTLER, 1997; 1993; DERRIDA, 1990). Isto significa afirmar que, quando falamos sobre como as coisas no mundo são ou como os eventos aconteceram, o que fazemos não é simplesmente descrever coisas ou eventos, mas produzir efeitos que constroem o que alegamos descrever. Além disso, o que falamos está submetido àquilo que Austin (1976) chamou de "circunstâncias apropriadas", sendo, portanto, ritualizado - isto é, dependente de contextos prévios de realização da fala.

No sentido de pensar sobre os contextos de realização de atos de fala, trazemos a resposta de Jacob Mey, em entrevista a Daniel Silva (2014), à pergunta sobre sua visão acerca do papel do intelectual, visto como alguém que, em alguma medida, traz uma abordagem pragmática:

Penso que todos os intelectuais adquirem alguma dose de pragmática em suas reflexões. E isso porque se um intelectual não é crítico, ele não é um intelectual. Um intelectual que apenas se subscreve às teorias correntes e às vertentes hegemônicas é uma pessoa que basicamente abdica de seu direito de ser intelectual. Um intelectual é crítico por definição. (SILVA, 2014, p. 177)

Como intelectual crítico, Blommaert (2014) examina a produção de metadiscursos especializados sobre a língua, dizendo que, historicamente, a linguística tem produzido uma representação particular de língua - a noção mesma de uma língua, (grifos do original), algo com um nome e algo sobre o qual podem ser produzidos artefatos gráficos e textuais particulares, tais como gramáticas, dicionários e manuais.

A primeira atividade gira sobre uma visão ideologicamente informada: a de que a língua é primária e essencialmente forma e estrutura (não, por exemplo, função), e que "uma língua" existe em relação a seus falantes em virtude do compartilhamento dessas formas e estruturas. A isso chamamos de ideologia artefatual da lingua: uma ideologia especialista em que a diversidade desconcertante que caracteriza a língua real em contextos reais ("fala") pode ser reduzida a apenas um punhado de formas 
e regras que organizam as combinações de tais formas. [...] A segunda proposição na ideologia artefatual de linguagem defende que essas formas e regras são tudo o que bá na língua - são "língua" e ponto final. Os artefatos de descrição e análise tornam-se metonimicamente a língua propriamente dita, e seus aprendizes são levados a estudá-los no intuito de se tornarem capazes de produzir a estonteante diversidade que caracteriza a língua real em contextos reais. (BLOMMAERT, 2014, p. 71, grifos do original)

Por sua vez, Rajagopalan (2014a) diz que, fora do universo da linguística, a questão por vezes não é tratada de modo tão pacífico, afirmando que o conceito de língua é pura invenção. Como frisa Davidson, "[e]le não existe in natura $[. .$.$] todos falamos tão livremente de língua, ou línguas, que$ tendemos a esquecer que essas coisas não existem no mundo real; o que existe são apenas pessoas e seus diversos produtos acústicos e escritos. Esse ponto, óbvio em si mesmo, é no entanto fácil de esquecer” (1992, p. 256). E Rajagopalan (2014a, p. 106) reafirma: "o que vem a ser o pior: não há nada na natureza que corresponda ao que chamamos de língua.

Situando melhor esse panorama político e linguístico, Pinto (2012; 2014) traz relevantes argumentos acerca dos consensos e contradições que cercam os discursos hegemônicos sobre língua no Brasil ao observar que estes discursos têm raízes no passado e muitas também no presente, que apresentam características de serem muito repetidos e grande capacidade de controle de seus efeitos e de sua própria reprodução, ou seja, são discursos hegemônicos.

De maneira geral, os discursos hegemônicos são dinâmicos e relacionais, dependentes de uma conjunção de vetores de força que disputam os sentidos da vida comum na construção performativa de consensos e coerções. Isso significa que, apesar de sua capacidade de controle e repetição, os discursos hegemônicos não são estáticos e nem soberanos sobre seus efeitos. Eles circulam em contradição uns com os outros, e experimentam tanto cumplicidade quanto resistência na sua atualidade local. (PINTO, 2014, p. 60)

A autora nos apresenta um minucioso estudo sobre as ações de controle dos Estados colonial e republicano, com apoio da igreja e das elites, e descreve como essas instituições participaram da construção das hegemonias em torno da interpretação da língua portuguesa, enfatizando que as ações do Estado e da Igreja foram acompanhadas de ações prescritivas na produção do conhecimento linguístico no Brasil. Essa produção foi 
explicitamente fundamentada no modelo filológico de estudos das línguas (a escrita como fonte principal de conhecimento sobre as línguas) e no modelo de escrita como evolução sociocognitiva (a escrita como ícone de civilização e da racionalidade), trazidos da Europa latina.

Como símbolo da civilização conquistadora, oposta à "naturalidade" da fala, "a escrita cristalizou-se como ícone da evolução dos povos e sinal de inteligência superior” (PINTO, 2014, p. 64). E conclui que os enunciados sobre língua no Brasil, atos de fala reiterados, compõem três hegemonias principais sobre nossa língua: a unidade linguística (ou variação monolíngue), a hierarquia escrita/oralidade e a correspondência linear língua/escrita/ cognição. Essas três hegemonias remetem a três modelos interpretativos que fincam raízes no século XVIII, ou seja, na consolidação da Modernidade colonial: o modelo romântico alemão de língua (uma língua, uma cultura, um povo), o modelo filológico de estudos das línguas (a escrita como fonte privilegiada de conhecimento sobre as línguas) e o modelo evolucionista de escrita (a escrita como ícone de evolução/civilização).

Indo ao encontro dos argumentos de Kramsch (2014) já mencionados nesta oportunidade, em torno da multiplicidade de códigos, meios e formas de dar sentido à vida, Pinto (2014) diz que os modos de interação também são alterados pelo incremento do modelo virtual de interação. Para as identidades, isso significa, entre outras coisas, a possibilidade de arranjos e cumplicidades antes restrita ao modelo de interação presencial.

Ainda retomando a fala de Kramsch (2014) acerca dos efeitos da globalização e das tecnologias de comunicação global, Mignolo (2003) diz que até o meio do século XX a diferença colonial respeitava a distinção clássica entre centros e periferias. Na segunda metade do século, a emergência do colonialismo global, gerenciado pelas corporações transnacionais, apagou a distinção que era válida para as formas inicias de colonialismo e colonialidade do poder. No passado, a diferença colonial situava-se lá fora, distante do centro. Hoje emerge em toda parte, na periferia dos centros e nos centros da periferia.

A diferença colonial é o espaço onde emerge a colonialidade do poder. A diferença colonial é o espaço onde as histórias locais que estão inventando e implementando os projetos globais encontram aquelas histórias locais que os recebem; é o espaço onde os projetos globais são forçados a adaptar-se, integrar-se ou onde são adotados, rejeitados ou ignorados. A diferença local é, finalmente, o local ao mesmo tempo físico e imaginário onde atua a colonialidade do poder, no confronto 
de duas espécies de histórias locais visíveis em diferentes espaços e tempos do planeta. Se a cosmologia ocidental é um ponto de referência historicamente inevitável, as múltiplas confrontações de dois tipos de histórias locais desafiam dicotomias. (MIGNOLO, 2003, p. 10)

A diferença colonial cria condições para situações dialógicas nas quais se encena, do ponto de vista subalterno, uma enunciação fraturada, como reação ao discurso e à perspectiva hegemônica. Assim, o pensamento liminar é mais do que uma enunciação híbrida (MIGNOLO, 2003). Nesse sentido, o pesquisador argentino sinaliza para o esforço em "compreender por que as coisas são como são e por que distinguir o 'período colonial' (expressão referente, sobretudo, à colonização espanhola e portuguesa) da 'colonialidade do poder' que hoje continua viva e saudável sob a forma de "colonialidade global"' (MIGNOLO, 2003, p. 16). Tratando dos saberes desqualificados pelo processo de colonização da missão colonizadora, Mignolo afirma que:

No século 16, missionários espanhóis julgavam e hierarquizavam a inteligência e civilização dos povos tomando como critério o fato de dominarem ou não a escrita alfabética. Esse foi um primeiro momento para a configuração da diferença colonial e para a construção do imaginário atlântico que irá constituir o imaginário do mundo colonial/ moderno. A tradução apresentava-se como o instrumento especial para estabelecer a diferença colonial no século 16 e utilizá-la nos séculos 18 e 19. O pensamento liminar [...] busca compensar a diferença colonial que a tradução colonial (sempre unidirecional, como a globalização em nossos dias) tentava naturalizar como parte da ordem universal. No século 16 a diferença colonial articulava-se espacialmente. A se aproximar o fim do século 18 e início do 19, o critério de avaliação já não era a escrita, mas a história. "Os povos sem história" situavam-se em um tempo "anterior" ao presente. Os povos "com história" sabiam escrever a dos povos que não a tinham. (MIGNOLO, 2003, p. 23)

Voltando a pensar sobre as práticas discursivas em torno do que se entende como "língua", complemento a argumentação de Pinto (2007; 2012; 2014), quando ela diz que as práticas identitárias constroem, então, redes interacionais locais e globais, reconfigurando fronteiras de grupos e, para isso, pluralizando as práticas linguísticas - um plurilinguajamento constitutivo, como aponta Mignolo (2003). Nesse contexto, as práticas identitárias contemporâneas dão suporte a duas contradições dos discursos hegemônicos sobre língua no Brasil. 
A primeira contradição ocorre no contexto de mudanças centrais no projeto do sistema mundo/moderno e confronta os modelos interpretativos que sustentam as hegemonias sobre língua. Por um lado, a ênfase nos grandes centros mercadológicos atua em direção oposta ao controle nacionalista do modelo romântico alemão, na medida em que torna transnacional qualquer ação (econômica, social, cultural, política, linguística); por outro lado, as forças de subjetivação do consumismo contemporâneo (satisfação imediata, provisoriedade, insegurança e fragilidade) e da textualidade digital (rapidez, fragmentação, excesso e lacunas) atuam contra os modelos filológico e evolucionista da escrita, na medida em que ameaçam a estabilidade e a linearidade da escrita e sua articulação interpretativa hierárquica em instituições modernas (Estado, Escola, Universidade). Esse contex to trabalha no sentido oposto às hegemonias aqui discutidas. [...] A segunda contradição ocorre no contexto da silenciosa e anônima perseverança do projeto moderno, a diferença colonial (MIGNOLO, 2003), que mantém a concepção temporal linear e hierárquica e, assim, os mesmos três modelos consolidados no século XVIII como parâmetros discursivos para se falar de língua. A diferença colonial é a insistência nos padrões de conhecimento e organização estabelecidos no contexto colonial e a consequente subalternização dos conhecimentos, das línguas, das culturas, das organizações sociais dos povos colonizados. Essa diferença colonial impede que interroguemos a permanência de ideias e argumentos fundados e sustentados nas relações coloniais e em seu momento histórico. Esse impedimento é parte das relações de poder sustentadas pela colonialidade, ou seja, pela continuidade das relações coloniais nas relações contemporâneas. A persistência simbólica da escrita monolíngue padronizada como espaço privilegiado de expressão da cognição é prova dessa perseverança. Mantendo a escrita como ícone da civilização e da razão e, em decorrência, imprimindo aos povos chamados "ágrafos" a alcunha de primitivos, a mídia e a instituição escolar, por exemplo, insistem que a oralidade, múltipla e heterogênea, é habilidade pré-escolar que não deve ser incentivada em sua prática cotidiana. Assim, o ensino de língua portuguesa permanece associado ao seu papel homogeneizante [...] e à centralidade da escrita. (PINTO, 2014, p. 66-68)

\section{Sobre agência e agenciamento}

Neste cenário em que se discute a colonialidade do saber, refletir sobre a diferença colonial no contexto da construção das hegemonias e dos discursos sobre linguagem escrita, dos conceitos de agência e do papel do agenciamento é fundamental para o intelectual crítico ao ter em conta que o conceito de língua é tênue, construído com base em discursos hegemônicos, 
os quais também são dinâmicos e relacionais, e que os aparelhos conceituais, de uma maneira geral, necessitam de constantes revisões e atualizações, por estarem sujeitos a papéis institucionais diversos.

Ahearn (2000) diz que:

O conceito de agência ganhou maior circulação no final da década de 1970, visto que estudiosos em muitas disciplinas reagiram contra o fracasso do estruturalismo de levar em conta as ações dos indivíduos. Inspirado por ativistas que desafiaram as estruturas de poder existentes, a fim de alcançar a igualdade racial e de gênero, alguns acadêmicos procuraram desenvolver novas teorias que fariam justiça aos efeitos potenciais da ação humana. (p. 12, tradução Joelma de Souza Rocha)

Vê-se, assim, que a necessidade de trazer os estudos sobre agência é oriunda dos efeitos potenciais da ação humana e essa ação ocorre, não só, mas também, por meio da linguagem, a qual "molda categorias de pensamento dos indivíduos ao mesmo tempo em que permite a eles às vezes transcender essas categorias" (AHEARN, 2000, p. 13, tradução Joelma de Souza Rocha). Ou seja, os estudos sobre agência permitem entender melhor os modelos estabelecidos, ir além deles, questioná-los e pô-los à prova a partir das necessidades que surgem, mas também adaptar-se a eles.

Como ressalta Ahearn, (2000, p. 13, tradução Joelma de Souza Rocha), "a linguagem é uma ação social, [...] a cultura, em todas as suas formas, emerge dialogicamente de interações linguísticas diárias, que são moldadas por formações socioculturais". Agência, portanto, refere-se à "capacidade socioculturalmente mediada para agir. [...] toda ação é socioculturalmente mediada, tanto na sua produção quanto na sua interpretação" e a cultura em todas as suas formas, como afirma Ahearn (2001), emerge todos os dias da agência linguística.

Por sua vez, Duranti (2004) diz que qualquer ato de fala envolve algum tipo de agência, muitas vezes independentemente das intenções do falante e do interesse ou colaboração do ouvinte.

Isto é devido ao fato de que ao falarmos nós estabelecemos uma realidade que tem, pelo menos, o potencial para afetar quem quer que esteja nos escutando, independentemente do público previsto inicialmente. Nós não afetamos somente a mente e as ações futuras dos nossos ouvintes quando fornecemos novas informações sobre o mundo [...] nós também os afetamos quando repetimos o que o nosso ouvinte já sabe. (p. 451, tradução Joelma de Souza Rocha) 
Ainda de acordo com Rajagopalan (2013), o agente não é simplesmente o sujeito da linguagem e, sim, aquele sujeito que pratica o agenciamento, ou seja, desafia as estruturas de poder existentes,

se distingue pela sua vontade de se auto afirmar e marcar o seu posicionamento, independentemente do grau do sucesso que ele tem na sua ousadia. Podemos dizer que ele é um sujeito que conseguiu furar o cerco da estrutura que o esmagava e tolhia a sua autonomia, desejo e direito de agir. (RAJAGOPALAN, 2013, p. 35)

Por outro lado, Asad (2000, p. 34, tradução nossa) diz que "agência tem o significado de representação. Neste sentido, as ações de um agente são tidas como as ações daqueles que o agente representa. O conceito de representação, central para esse significado de agência, tem sido objeto de debate de longa data na teoria política ocidental”.

De fato, o conceito de representação (e a tese do representacionismo), embora bastante criticado, não pode ser ignorado, uma vez que orienta muitos estudos e ações sobre as práticas de linguagem e as práticas sociais diversas. Concordo com Rajagopalan (2003) quando ele discute as políticas de representação e diz que a "a tese do representacionismo na verdade esconde o sonho da apresentação" (RAJAGOPALAN, 2003, p. 31, grifo do original). Entretanto, uma vez que estamos falando de uma tese que orienta uma parcela significativa do pensamento e do trabalho intelectual e, portanto, parte do aparato teórico e metodológico adotado pela comunidade acadêmica, é preciso tê-la em conta.

Conforme discuti em momentos anteriores (CORREA, 2009; 2011a; 2014) com base em Britto (2008), os modos de representação, de organização e de estruturação social resultam de um processo que se fez historicamente com base na língua escrita, o que constituiu um pensar escrito. Poder ler e escrever, interagir com os textos escritos e com os conhecimentos e informações que se veiculam desta forma, tudo isso é condição essencial de participação social.

Em Rethinking writing, Roy Harris (2000) discute a questão da representação para descrever e defender o integracionismo. As principais características do integracionismo, segundo o autor, são:

- a linguística integracionista toma como ponto de partida a tentativa dos seres humanos de integrar as atividades de comunicação e não somente o objeto chamado língua, de maneira que linguagem não pode ser dissociada de comunicação; 
- o conhecimento linguístico está integrado, de maneira complexa, ao extralinguístico.

Harris (2000) retoma Michel Foucault e Ferdinand de Saussure para abordar a natureza binária do signo, considerando-a uma das fundações essenciais das teorias ocidentais de representação. Para este integracionista, Saussure fez avanços, embora tenha sido muito conservador nesse respeito e, embora a definição de signo de Saussure tenha sido relevante, na verdade foi uma forma de restabelecer a condição clássica de conceituar a natureza binária do signo.

Ainda, ao comparar e avaliar os estudos de Saussure e de Pierce, Harris (2000) entende que as questões sobre escrita ficaram em aberto no legado dos dois estudiosos, uma vez que Pierce as protelou e Saussure as excluiu. Assim, em ambos os casos, fornece-se uma base independente e viável para repensar a escrita, conforme veremos adiante.

Assim, o papel do agente é de extrema importância quando se discute questões de linguagem escrita. As razões são oriundas de variáveis diversas, conforme vimos, e a construção do pensamento hegemônico entretece os agenciamentos. No conjunto das ações humanas, os efeitos dessas ações são intrínsecos e as agências, sejam do ponto de vista das ações sociais ou da representação, sempre afetam as pessoas, como bem aponta Duranti (2004).

Os agenciamentos entremostram os consensos e as contradições presentes nos discursos sobre língua e sobre linguagem escrita na medida em que as hegemonias são pautadas pelos modelos consolidados historicamente, conforme apontado por Pinto (2014). Entretanto, os novos modos de interação citados por Pinto e também por Kramsch (2014) ratificam que o conceito de língua é insustentável, da mesma forma que a supremacia da escrita segundo o modelo monolíngue padronizado.

\section{Dois exemplos de circunstâncias apropriadas sobre escrita}

Os discursos em torno das festas de final e início de ano circulam nos mais diversos segmentos de mídia e também nos institucionais, e a troca de presentes é uma das práticas incentivadas neste momento.

Entre as crianças, alimenta-se uma expectativa de que todas receberão algum presente na festa religiosa do natal, não raro, vários. Entretanto, no Brasil essa não é a realidade para as crianças que fazem parte das classes sociais menos favorecidas, portanto, pertencentes a comunidades 
vulneráveis. Por essa razão, é habitual encontrarmos cartinhas de natal nas caixas de correio das residências durante o mês de dezembro. $\mathrm{Na}$ maioria das vezes, crianças pedem material escolar, brinquedos ou mesmo alimentos, mas a carta abaixo chama a atenção pelo presente solicitado.

Trata-se de uma cartinha deixada na minha caixa de correio durante o período em que estava escrevendo este artigo, razão pela qual decidi trazê-la para a discussão, por ser propícia para (de)compor algumas ideias acerca da escrita hegemônica.

FIGURA 1: Carta de Natal encontrada na caixa de correio em 10 de dezembro de 2016.

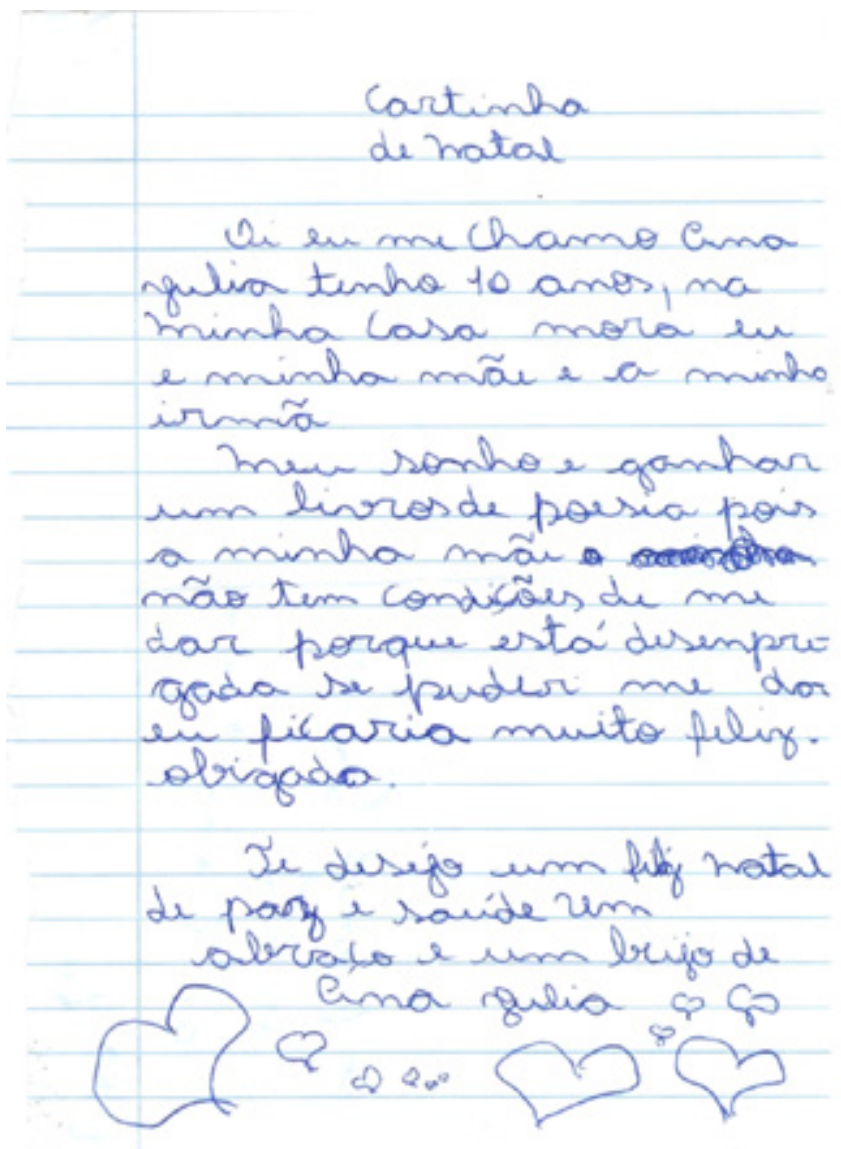

Ana Julia tem 10 anos de idade e, no momento em que escrevo este texto, não há como saber se ela está no ciclo 1 ou no ciclo 2 do ensino fundamental, embora os indícios, pela faixa etária, sejam de que deva 
estar na transição entre os dois ciclos. O que é possível constatar é que ela tanto pode gostar de poesia quanto pode querer ter um livro de poesia. Concomitantemente à manifestação desse interesse por poesia ou livro de poesia, observamos que a menina pratica uma forma de agenciamento que reitera um modelo de interação canônico e a relevância do gênero literário.

Seja qual for a motivação, é inegável que o pedido é peculiar em tempos de índices alarmantes de analfabetismo divulgados amiúde nos segmentos hegemônicos de mídia, de propostas polêmicas de mudanças para o ensino médio diante de tais índices, as quais estão em discussão, entre outros.

Para mencionar índices, no mesmo período em que escrevia este texto, em meados de dezembro, deparei-me com a seguinte chamada em uma reportagem veiculada na página de um servidor de internet bastante acessado e prestigiado: "Um cara que não sabe ler é um cego da vida" (MOURA; CARICATI; MANDIL, 2016), resume José Webson da Silva, 22, sobre sua própria condição.

A matéria traz relatos de pessoas jovens "em busca das letras" e classifica São Paulo como a terra das promessas, uma metrópole cheia de histórias de gente que não sabe ler nem escrever um bilhete. E segue com uma sequência de relatos, de quem perdeu o emprego porque não conseguiu preencher a ficha do processo seletivo, só enviava áudios pelo WhatsApp e chegou a ficar perdido na estação Sé do metrô porque não entendia as placas.

Após essa apresentação, a matéria apresenta dados de pesquisa e estatísticos sobre analfabetismo e analfabetismo funcional, os quais não vou reproduzir aqui por considerar convincentes aqueles sobre os quais já temos conhecimento. São números colhidos pelo Instituto Paulo Montenegro em parceria com o Ibope e divulgados neste ano, fazendo parte do Indicador de Analfabetismo Funcional (Inaf), criado para aferir o grau de alfabetização dos brasileiros.

A pesquisa classifica os brasileiros em cinco grupos de diferentes níveis de alfabetização: analfabeto, rudimentar, elementar, intermediário e proficiente, sendo que: analfabeto absoluto é aquele que não consegue realizar tarefas simples, como ler palavras e frases; o nível rudimentar de alfabetização reúne quem é capaz apenas de localizar informações explícitas em textos muito simples, como calendários e cartazes com sentenças ou palavras relacionadas ao seu cotidiano, e ler e escrever números familiares como horários, preços e cédulas de dinheiro. A partir do nível elementar, 
os testes exigem habilidade crescente de leitura e escrita, com identificação de informações em textos de extensão média até elevada complexidade, e realização de operações básicas com números da ordem do milhar até a interpretação de tabelas e gráficos.

Em complemento, traz o depoimento de Maristela Miranda, diretora do Programa Alfabetização Solidária: "É uma tragédia para esses jovens. Vivemos em um mundo letrado, que exige, a todo o momento, que a gente se posicione de várias maneiras. E a principal qual é? Uma cultura de mundo letrado. Então, como esse jovem se vira dentro desse mundo?”.

Os dois exemplos ilustram e esclarecem as contradições e os consensos trazidos por Pinto (2012) e principalmente reiteram os modelos filológico e evolucionista apresentados pela pesquisadora e já trazidos nesta oportunidade. Harris (2000) já havia feito observações relevantes para o tema:

Um comentário parece necessário neste ponto acerca de uma das noções mais críticas sobre a escrita que é cara a alguns estudiosos das ciências humanas. Ela interfere nas nossas preocupações presentes porque o que presume é que o valor de uma civilização será em última instância julgado por sua "literatura". Por isso, a restrição curiosa do termo escrita e do verbo escrever aplicados à produção de redações para fins de alfabetização. (p. 8-9, tradução Silvana Aparecida Carvalho do Prado)

Por outro lado, conforme já ressaltei em outras ocasiões, nas palavras de Britto (2008, p. 282), "como recurso inerente e propício à participação social, por tornar compartilhável o pensamento e as ideias, os movimentos, os exercícios de busca, de sistematização, a escrita consiste, reiterando, em um influente instrumento intelectual e de organização social”. Assim, ela permite um nível de controle da atividade intelectual que não se encontra na mesma intensidade em outras formas de registro (BRITTO, 2008). O autor refere-se ao modo como se dá o envolvimento do sujeito com o texto, o ritmo das ações, a possibilidade de controle quase pleno da ação, as formas de intervenção consciente no fluxo do pensamento. São características que contribuem enormemente para a atividade metacognitiva. A metacognição - entendida como o ato de controlar o próprio pensar, a administração deliberada das formas de raciocínio e de interação - torna uma atividade como a escrita particularmente significativa no processo de constituição da consciência, no estabelecimento dos valores e nas formas de intervenção no tecido social (BRIT'TO, 2008). 
E neste ponto, quando essa visão mais utilitária da escrita, como organizadora do pensamento com vistas ao desenvolvimento metacognitivo, é lembrada é preciso trazer o contraponto, por isso, voltamos a Harris (2000):

Uma sociedade pode permanecer nesse estágio por um tempo muito longo. As pessoas podem não entender como a escrita tem reformulado inteiramente seu entendimento de mundo, porque elas ainda se remetem à antiga premissa de que escrever é apenas uma alternativa útil, ou no melhor dos casos, uma melhoria da comunicação oral. Esse é o estágio no qual ainda estamos hoje, e no qual permaneceremos enquanto nós continuarmos a nos congratular pelo progresso na erradicação do "analfabetismo", o de considerar a leitura dos livros certos como base de toda a educação, e adiar o repensar da escrita que já está bem atrasado. (p. XIII, tradução Silvana Aparecida Carvalho do Prado)

Ainda a título de retomada de trabalhos anteriores, conforme Britto (2008), o caráter grafocêntrico da sociedade ocidental confere à escrita um status que está circunscrito ao desenvolvimento intelectual e social em que a leitura e a escrita são instrumentos essenciais de participação. Como vimos nos depoimentos e dados estatísticos trazidos no segundo exemplo, os parâmetros de pesquisa têm o objetivo de categorizar e classificar pessoas pelos níveis de alfabetização. Na mesma direção, temos os parâmetros de avaliação da educação básica, média e superior, ou seja, ainda se levam em conta, basicamente, os critérios associados ao grafocentrismo e às habilidades de ler e escrever. Portanto, são parâmetros que desconsideram os meios de interação não presencial. Observemos que um dos entrevistados associa as dificuldades que tem ao fato de utilizar mensagens de voz ou áudios no WhatsApp.

A partir dos pontos de vista que instauram as contradições sobre escrita que tentei trazer por meio dos exemplos, é possível retomar os efeitos da colonialidade e a insistência em manter a herança da Modernidade colonial, como ressalta Mignolo (2003). Da mesma forma, vemos que atos de fala reiterados compõem as hegemonias sobre língua trazidas por Pinto (2012), que atuam na consolidação da Modernidade colonial por meio da permanência dos modelos interpretativos de estudos de língua.

Por conseguinte, instauram-se as contradições que, de um lado, mantêm e sustentam essas hegemonias sobre a unidade linguística, a preponderância da escrita em detrimento da fala e a correspondência linear entre língua, escrita e cognição. De outro lado, reconhece-se que essas hegemonias não condizem com as mudanças do mundo moderno. 


\section{Sobre escrita e pragmática}

Voltando o foco para o protagonismo da linguagem escrita, na apresentação do livro Nova pragmática (2014), encontramos uma menção muito oportuna a Caio Fernando Abreu, o qual "escreveu como nota à última revisão que fez de Morangos mofados que 'textos, como as pessoas, são vivos e sempre podem melhorar em sua contínua transformação"”.

As/os organizadoras/es do livro (SILVA; FERREIRA; ALENCAR, 2014, p. 9) complementam: "De fato, os textos têm vida - e a sua vida consiste em estágios de mudança contínua, os quais se fixam temporariamente em formas sonoras, impressas ou multimodais, até viajarem para outros lugares e ganharem novas feições".

Na mesma obra, Mey (2014) escreve que atos de fala dependem da situação para a correta interpretação, de modo que não há fala que, por si mesmo, faça sentido. Portanto, há somente atos de fala situados ou pragmáticos.

Tomando a linguagem como ação social, a Nova pragmática, conforme termo de Rajagopalan (2014c, p. 13): "nada mais é do que a fase da Pragmática que conseguiu se desvencilhar das velhas amarras herdadas de outros tempos, que impediam os pesquisadores de encarar a linguagem com todas as complexidades que ela apresenta sem lhes dar costas ou simplesmente menosprezá-las em nome do aperfeiçoamento da teoria”. Retomo assim a Mey (2014) quando ele diz que o intelectual é crítico por definição, para citar Mignolo (2003), fazendo referência à ideia de texto e tecido, trazendo à tona o capítulo de Gloria Anzaldúa sobre a escrita asteca "Tlilli, Tlapalli: o caminho da tinta vermelha e negra".

Benedict Anderson ([1983] 1991), em seu livro clássico, presta grande e significativa atenção ao papel da imprensa na construção das comunidades nacionais. Antes do século 19, a imprensa foi também decisiva para o processo de expansão colonial, do controle territorial à literalidade e educação. A noção de "texto" ficou cada vez mais limitada à literalidade alfabética e ao livro, e certos livros contendo narrativas nacionais tornaram-se ícones nacionais. Todas as outras formas escritas foram automaticamente relegadas ao reino do folclore, à dimensão subalterna do conceito de cultura do estado-nação. Em "Tlilli, Tlapalli: o caminho da tinta vermelha e negra" Anzaldúa traz à tona uma dimensão de "texto e nação" duas vezes suprimida: uma vez no início do sistema colonial de educação, e depois pela convicção dos construtores da nação de que a nação e a civilidade fundavam-se parcialmente na literalidade alfabética. 
A rearticulação de língua e escrita pelo estado-nação efetivou uma dupla subalternização da escrita: primeiro, ao elevar a escrita alfabética ao cume da civilidade e, segundo, ao manter uma divisão de gênero entre as práticas de escrita. "Homens de letras" controlavam a literalidade dentro do aparato estatal; os "texteis" ficaram nas mãos de mulheres e no reino do folclore. Ao resgatar os antigos sistemas de escrita, o "caminho da tinta vermelha e negra", Anzaldúa renova a conceituação de escrita e texto e escancara as portas para repensar as cumplicidades entre textos, nações, impérios e culturas do saber acadêmico. (MIGNOLO, 2003, p. 354)

Para nos livrar das amarras subscritas às teorias correntes e vertentes hegemônicas, reitero as muitas vozes que introduziram este texto. Para pensar no(s) protagonista(s) ou no protagonismo da linguagem escrita, é preciso, antes, pensar que a linguagem é uma ação social e que a agência é uma capacidade socioculturalmente mediada pelo agir.

Com essas premissas, os protagonistas se definem a partir dos papéis sociais que têm ou que assumem, ou não. E os papéis de liderança nessa organização não são construídos individualmente, são construções performativas de consensos e coerções, como vimos. Ao propor repensar a escrita, Harris (2000) nos mostra que:

Uma perspectiva integracionista então reverte a prioridade tomada como certa nos relatos tradicionais de escrita. A atenção é concentrada não em algum sistema de supostas correlações entre os signos escritos e falados, mas sobre as particularidades da comunicação escrita em circunstâncias específicas. Mas essa reversão das prioridades leva a outras. (p. 82)

A ideia de protagonismo supõe autonomia, na medida em que a ideia de autogoverno e soberania é tentadora. Entretanto, os protagonistas são agentes e como tais são submetidos a consensos hegemônicos prévios e, como vimos em Pinto, os discursos hegemônicos não são estáticos nem soberanos sobre seus efeitos, de modo que circulam em contradição uns com os outros e experimentam cumplicidade e resistência, podendo conseguir ultrapassar as barreiras da estrutura ou não. Por essa razão, entre o desejo de autonomia para agir socialmente, o direito de tê-la e a ação efetiva está a necessidade de repensar continuamente os aparelhos conceituais que constroem os modos de interação, notadamente o conhecimento acadêmico e, de maneira mais específica, os novos modos de interação que dizem respeito à linguagem escrita. 


\section{Considerações finais}

Entre os saberes desqualificados pelo processo de colonização, o conhecimento acadêmico continua a privilegiar configurações de conhecimentos que negam possibilidades epistemológicas. Por essa razão, é importante atentar, como sugere Mignolo (2003), para as políticas e sensibilidades de locais na produção, exportação e importação do conhecimento e esforçar-se em compreender por que as coisas são como são e por que temos que distinguir o "período colonial" da "colonialidade do poder", que hoje continua viva e saudável sob a forma da "colonialidade global".

Ainda inspirada nos estudos e argumentos de Mignolo (2003), temos outras escolhas, até a possibilidade de preferir pensar nas e a partir das margens, de adotarmos o pensamento liminar como futura ruptura epistemológica. O pensamento liminar poderia abrir as portas para outro pensamento, superando a longa história do mundo colonial /moderno, da colonialidade do poder, da subalternização dos saberes e da diferença colonial.

Dessa forma, temos outras possibilidades de repensar o protagonismo da linguagem escrita, expandir, problematizar e compreender melhor as contradições que constroem os discursos em torno da visão homogênea, linear e central de língua e, de maneira mais específica, de linguagem escrita. Da mesma forma, podemos recuperar saberes desqualificados pelo processo de colonização, entender melhor as contradições oriundas da colonialidade do saber e, dessa forma, posicionarmo-nos melhor em relação a elas, discutindo a missão colonizadora mediante parâmetros e configurações de conhecimentos que não neguem possibilidades epistemológicas.

\section{Referências}

AHEARN, L. M. Agency. Journal of Linguistic Anthropology, South Carolina, v. 9, n. 1-2, p. 12-15, 2000.

AHEARN, L. M. Language and agency. Annual Review of Anthropology, California, v. 30, p. 109-137, 2001. https://doi.org/10.1146/annurev.anthro.30.1.109.

ASAD, T. Agency and pain: an exploration. Culture and Religion, New York, v. 1, n. 1, p. 29-60, 2000. https://doi.org/10.1080/01438300008567139.

AUSTIN, J. L. How to do things with words. 2. ed. Oxford: Oxford University Press, 1976.

BLOMMAERT, J. Ideologias linguísticas e poder. (Trad. de Ive Brunelli). In: SILVA, D. N.; FERREIRA, D. M. M.; ALENCAR, C. N. (Org.). Nova pragmática: modos de fazer. São Paulo: Cortez, 2014. p. 67-77. 
BRITTO, L. P. L. Educação linguística escolar: para além das obviedades. In: CORREA, D. A.; SALEH, P. B. O. (Org.). Estudos da linguagem e curriculo de Letras: diálogos (im)possíveis. Ponta Grossa: EdUEPG, 2008. p. 15-29.

BUTLER, J. Excitable speech: a politics of the performative. New York: Routledge, 1997.

CORREA, D. A. Aspects of writing and identity. Language Sciences, Oxford, v. 33, n. 4, p. 667-671, 2011a. https://doi.org/10.1016/j.langsci.2011.04.012.

CORREA, D. A. Política linguística e ensino de língua. Calidoscópio, São Leopoldo, v. 7, n. 1, p. 69-75, 2009. https://doi.org/10.4013/cld.2009.71.07.

CORREA, D. A. Políticas linguísticas e ensino: um convite à discussão. In: BATTISTI, E.; COLLISCHONN, G. (Org.). Lingua e linguagens: perspectivas de investigação. Pelotas: Educat, 2011b. p. 105-124.

CORREA, D. A. Práticas linguísticas e ensino de língua: variáveis políticas. In: CORREA, D. A. (Org.). Politica linguística e ensino de lingua. Campinas: Pontes, 2014. p. 19-35.

CORREA, D. A.; GÜTHS, T. R. Por um constante repensar de nossas visões sobre língua: revisitando o conceito de política linguística. Cadernos de Linguagem e Sociedade, Brasilia, DF, v. 16, n. 2, p. 140-159, 2015.

DAVIDSON, D. The second person. Midwest Studies in Philosophy, Hoboken, v. 17, n. 1, p. 255-267, 1992. https://doi.org/10.1111/j.1475-4975.1992.tb00154.x.

DERRIDA, J. Limited Inc. Paris: Galilée, 1990.

DURANTI, A. Agency in language. In: DURANTI, A. (Ed.). A companion to linguistic anthropology. Massachusetts: Blackwell Publishing, 2004. p. 451-473.

HARDY-VALLÉE, B. Que é um conceito? São Paulo: Parábola, 2013.

HARRIS, R. Retbinking writing. London: Continuum, 2000.

JOSEPH, J. E. Language and politics. Edimburgo: Edinburgh University Press, 2006. https://doi.org/10.3366/edinburgh/9780748624522.001.0001.

KRAMSCH, C. Por que os professores de língua estrangeira precisam ter uma perspectiva multilíngue e o que isto significa para sua prática de ensino. In: CORREA, D. A. (Org.). Política linguística e ensino de lingua. Campinas: Pontes, 2014. p. 11-20.

MEY, J. Sequencialidade, contexto e forma linguística. In: SILVA, D. N.; FERREIRA, D. M. M.; ALENCAR, C. N. (Org.). Nova pragmática: modos de fazer. Trad. Ive Brunelli. São Paulo: Cortez, 2014. p. 129-144.

MIGNOLO, W. D. Histórias locais/projetos globais - colonialidade, saberes subalternos e pensamento liminar. Trad. Solange Ribeiro de Oliveira. Belo Horizonte: UFMG, 2003. 
MOURA, D.; CARICATI, L.; MANDIL, J. Analfabetismo no século 21: jovens contam como é viver sem ler nem escrever na cidade de São Paulo. UOL Educaşão, São Paulo, 2016. Disponível em: <http://www.uol/educacao/especiais/ escolaridade-zero.htm\#tematico-1>. Acesso em: 14 dez. 2016.

PINTO, J. P. Conexões teóricas entre performatividade, corpo e identidades. Delta, São Paulo, v. 23, n. 1, p. 1-26, 2007. https://doi.org/10.1590/s010244502007000100001.

PINTO, J. P. Da língua-objeto à práxis linguística: desarticulações e rearticulações contra hegemônicas. Linguagem em Foco, Fortaleza, v. 2, n. 2, p. 69-83, 2010.

PINTO, J. P. De diferenças e hierarquias no quadro Adelaide às análises situadas e críticas na Linguística Aplicada. Delta, São Paulo, v. 31, p. 199-221, 2015.

PINTO, J. P. Hegemonias, contradições e desafios em discursos sobre língua no Brasil. In: CORREA, D. A. (Org.). Política linguística e ensino de lingua. Campinas: Pontes, 2014. p. 59-72.

PINTO, J. P. Modernidade e diferença colonial nos discursos hegemônicos sobre língua no Brasil. Muitas Vozes, Ponta Grossa, v. 1, p. 171-180, 2012. https:/ / doi. org/10.5212/MuitasVozes.v.1i2.0001.

RAJAGOPALAN, K. A pesquisa política e socialmente compromissada em pragmática. In: SILVA, D. N.; FERREIRA, D. M. M.; ALENCAR, C. N. (Org.). Nova pragmática: modos de fazer. São Paulo: Cortez, 2014a. p. 101-128.

RAJAGOPALAN, K. O professor de línguas e a suma importância do seu entrosamento na política linguística do seu país. In: CORREA, D. A. Política linguística e ensino de língua. Campinas: Pontes, 2014b. p. 73-82.

RAJAGOPALAN, K. Política linguística: do que é que se trata, afinal? In: NICOLAIDES, C. et al. (Org.). Politica e politicas linguísticas. Campinas: Pontes, 2013. p. 19-42.

RAJAGOPALAN, K. Por uma linguística crítica: linguagem, identidade e a questão ética. São Paulo: Parábola, 2003.

RAJAGOPALAN, K. Prefácio In: SILVA, D. N.; FERREIRA, D. M. M.; ALENCAR, C. N. (Org.). Nova pragmática: modos de fazer. São Paulo: Cortez, 2014c. p. 11-14.

SILVA, D. N. Pragmática, sociedade (e a alma), uma entrevista com Jacob Mey. Delta, São Paulo, v. 30, n. 1, 2014. p. 161-179. https://doi.org/10.1590/s010244502014000100009.

Data de submissão: 15/01/2017. Data de aprovação: 10/03/2017. 
